\title{
Kylmän kasvatusympäristön vaikutus ay-rotuisten lihanautojen tuotantotu- loksiin ja lihan laatuun
}

\author{
Arto Huuskonen ${ }^{1)}$, Markku Honkavaara ${ }^{2)}$ ja Erkki Joki-Tokola ${ }^{1)}$ \\ ${ }^{1)}$ MTT, Pohjois-Pohjanmaan tutkimusasema,92400 Ruukki,etunimi.sukunimi@mtt.fi \\ ${ }^{2)}$ Lihateollisuuden tutkimuskeskus, PL 56,13101 Hämeenlinna, markku.honkavaara@ltk.inet.fi
}

\begin{abstract}
Johdanto
Aiemmissa tutkimuksissa on osoitettu, että liharotuisia sonneja (Huuskonen ym. 2002) ja hiehoja (Manninen ym. 2002) voidaan kasvattaa myös kylmissä ympäristöissä ilman, että eläinten tuotantotulokset oleellisesti muuttuisivat. Tässä tutkimuksessa selvitettiin kylmien kasvatusympäristöjen vaikutusta teuraaksi kasvatettavien, ayrshire-rotuisten lihanautojen tuotantotuloksiin ja lihan laatuun.
\end{abstract}

\section{Aineisto ja menetelmät}

Koe-eläimet (30 ay-sonnivasikkaa) hankittiin Pohjois-Pohjanmaan tutkimusasemalle kesäkuussa 2000 A-Tuottajien eläinvälityksestä kahden viikon ikäisinä ternivasikoina. Vasikat sijoitettiin kylmäpihattoon ja nupoutettiin. Tässä raportoidun kasvatuskokeen alkaessa (marraskuussa 2000) eläimet olivat keskimäärin 159 vrk:n ikäisiä. Kokeen aluksi sonnit ryhmiteltiin elopainon perusteella kuuteen koeryhmään, joista kaksi (kummassakin 5 eläintä) jäi lämpimään parsinavettaan. Kaksi koeryhmää (5 eläintä/ryhmä) siirrettiin kylmäpihattoon, jossa ne sijoitettiin kahteen eri ryhmäkarsinaan. Kaksi viiden eläimen ryhmää sijoitettiin metsätarhaan, joka jaettiin väliaidalla kahteen osaan.

Navetan sonnit kasvatettiin ritiläpohjaisessa parressa, ja niillä ei ollut jaloittelumahdollisuutta. Kylmäpihatto oli kolmiseinäinen rakennus, jossa karsina-alue muodostui lantakäytävästä ja kuivikepohjasta. Karsinassa oli liikkumatilaa $6,4 \mathrm{~m}^{2} / \mathrm{eläin}$. Karsinan etuosassa sijaitsevalla ruokintapöydällä oli syöntitilaa $76 \mathrm{~cm}$ eläintä kohti. Kuivikepohjan päälle syntyvää makuualuetta kuivitettiin silputulla oljella tarpeen mukaan. Kuivikepohja tyhjennettiin säännöllisesti, samoin kuin lantakäytävälle kertynyt lanta. Metsätarha-alue oli nuorta sekametsää, joka jaettiin puoliksi kahdelle ryhmälle. Eläintä kohti käytettävissä oleva ala oli 0,1 ha. Tarhaan rakennettiin pulpettikattoinen, kolmiseinäinen suojarakennus, joka puolitettiin väliseinän avulla kahden koeryhmän käyttöön. Suojarakennuksen etuosassa sijaitsevalla ruokintapöydällä oli syöntitilaa $100 \mathrm{~cm}$ eläintä kohti. Rakennuksen takaosaan muotoiltiin hiekasta vinokuivikepohja, jonka päälle syntyvä makuuala oli kooltaan $3,2 \mathrm{~m}^{2} / \mathrm{eläin}$. Makuualustaa käytettiin kestokuivikepohjan tavoin niin, että makuupohjalle varauduttiin lisäämään silputtua olkea 2,5 - 5,0 kg/eläin/päivä.

Sonnit ruokittiin vapaasti seosrehulla, jonka kuiva-ainemäärästä hieman yli $40 \%$ koostui esikuivatusta nurmisäilörehusta ja loppuosa kuivana litistetystä ohrasta. Säilörehun raakavalkuaispitoi-

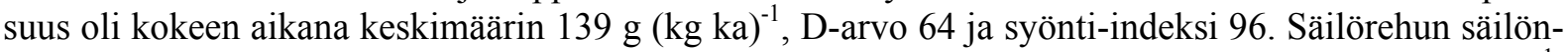
nällinen laatu oli hyvä. Rehuseoksen kuiva-ainepitoisuus oli kokeen aikana keskimäärin $441 \mathrm{~g}(\mathrm{~kg})^{-1}$. Rehun jako tapahtui kaksi kertaa päivässä, ja ruokinnassa huolehdittiin myös eläinten kivennäisaineiden sekä vitamiinien tarpeesta. Puhdasta juomavettä eläimet saivat vapaasti. Rehun ja veden kulutus mitattiin päivittäin.

Sonnit teurastettiin Atrian Kuopion teurastamolla normaalin teurastuskäytännön mukaisesti. Ruhojen lihakkuus luokiteltiin EUROP-luokituksella, jossa E kuvaa erittäin lihakasta ja P lihakkuudeltaan heikkoa ruhoa. Ruhojen rasvaisuus luokiteltiin asteikolla $1-5$, jossa 1 on rasvaton ja 5 erittäin rasvainen ruho. Jokaisesta kasvatusympäristöstä valittiin neljä mahdollisimman samanikäistä ja painoista eläintä lihanlaatututkimuksiin. Lihanäyteruhoista otettiin teurastuksen yhteydessä ulkofilenäyte (noin $5 \mathrm{~kg}$ ) lihan laadun arviointia varten. Teuraslinjalla mitattiin lihanäyteruhojen $\mathrm{pH}$-arvo ja lämpötila ulkofileestä 11 . kylkiluun kohdalta noin $5 \mathrm{~cm}: n$ syvyydeltä. Sama mittaus tapahtui $50 \mathrm{~min}, 5$ $\mathrm{h}$ ja $24 \mathrm{~h}$ teurastuksesta. Tällä haluttiin selvittää ruhon jäähtymisnopeus ja pH:n alenemisnopeus. Lihanäytteet pakattiin vakuumiin, minkä jälkeen niitä säilytettiin kolme viikkoa $+4{ }^{\circ} \mathrm{C}$ :ssa. Raakakypsyneestä ulkofileestä analysoitiin valuma (lihasta irronnut vesi, \%), vesi-, proteiini- ja lihaksen sisäinen rasvapitoisuus, rasvahappokoostumus, myoglobiinipitoisuus, leikkuupinnan väri (Minolta Chroma Meter CR-2000 mittari) ja leikkuuvaste (Instron-konsistometri, Warner-Bratzler -terä, Miller 1994). Aistinvaraisessa arvioinnissa määritettiin mureus, mehukkuus ja maku kypsennetystä lihasta. Lihan laatuanalyysit suoritettiin Lihateollisuuden tutkimuskeskuksella.

Tuotantotulosten tilastollinen käsittely tehtiin SAS-ohjelmiston varianssianalyysillä. Koekäsittelynä oli eläimen kasvatusympäristö. Kullakin koekäsittelyllä oli kaksi toistoa. Kylmäpihatossa ja ulko- 
tarhassa toistot muodostuivat kahdesta väliaidan toisistaan erottamasta viiden eläimen ryhmästä. Navetassa eläimet olivat yksittäisparsissa, mutta niistä muodostettiin koetulosten laskentaa varten kaksi viiden eläimen ryhmää. Käsittelyjen väliset erot testattiin kontrasteina: lämmin vs. kylmä ja pihatto vs. metsätarha. Lihanlaatuanalyysitulosten osalta kasvatusympäristöjen välisen eron merkitsevyys testattiin riippumattomien ryhmien varianssianalyysillä (anova) sekä Mann-Whitney -testillä.

\section{Tulokset ja tulosten tarkastelu}

Sonnien elopaino oli kokeen alkaessa keskimäärin $185 \mathrm{~kg}$. Sonnit teurastettiin puolentoista vuoden iässä joulukuussa 2001. Niiden päiväkasvu oli kokeen aikana keskimäärin $1030 \mathrm{~g} \mathrm{~d}^{-1}$ ja elopaino teurastettaessa keskimäärin $602 \mathrm{~kg}$. Kasvatusympäristö ei vaikuttanut tilastollisesti merkitsevästi eläinten kasvunopeuteen (taulukko 1). Kaikilla ryhmillä kasvutulokset olivat heikohkoja, mikä johtui todennäköisesti nurmisäilörehun heikosta sulavuudesta. Navettaan ruokitut sonnit kuluttivat sekä ruokintapäiviä että tuottamiaan teuraskiloja kohti laskettuna vähemmän rehua kuin ulkona kasvatetut eläimet (taulukko 1). Ulkona kasvatettujen eläinten suurempi rehunkulutus johtui osaksi sääolosuhteista ja liikunnasta. Elimistön energiavarastoja ja tätä kautta myös rehuenergiaa käytettiin sekä kylmäpihatossa että metsätarhassa lämmönmuodostukseen, mikä vaikutti negatiivisesti rehuhyötysuhteeseen.

Sonnien keskimääräinen ruohopaino oli $307,5 \mathrm{~kg}$. Teurasprosentit olivat kylmäpihatto- $(51,5 \%)$ ja metsätarhanaudoilla $(51,6 \%)$ hieman parsinavetassa kasvaneita sonneja $(50,0 \%)$ suuremmat. Niin ikään ruhojen lihakkuudessa kylmäpihatto- ja metsätarhasonnit saivat parsieläimiä paremman arvostelun (taulukko 1). Lihakkuuden osalta tulos oli tilastollisesti suuntaa-antava $(\mathrm{P}<0.1)$, mutta teurasprosenteissa ryhmien väliset erot eivät olleet tilastollisesti merkitseviä $(\mathrm{P}=0.15)$. Tämä johtui siitä, että teurasprosenttien osalta eläinkohtainen vaihtelu ryhmien sisällä oli suhteellisen suuri. Parsinavetan eläinten ruhot arvioitiin rasvaisuusluokituksessa pääosin keskirasvaisiksi (EUROP-luokka 3), kun suurin osa kylmäpihaton ja metsätarhan ruhoista olivat ohutrasvaisia (EUROP-luokka 2). Rasvaisuusluokituksen osalta tulos oli tilastollisesti merkitsevä (lämmin parsi vs. kylmät tuotantotilat, $\mathrm{P}<0.05$ ).

Taulukko 1. Tuotantotulokset eri kasvatusympäristöissä.

\begin{tabular}{|c|c|c|c|c|c|}
\hline & \multirow[t]{2}{*}{ Navetta } & \multirow[t]{2}{*}{ Pihatto } & \multirow[t]{2}{*}{ Metsätarha } & \multirow[t]{2}{*}{ SEM $^{1)}$} & Tilastollinen merkitsevyys ${ }^{2}$ \\
\hline & & & & & $\begin{array}{ll}\mathrm{C} 1 & \mathrm{C} 2\end{array}$ \\
\hline Eläinten lukumäärä & 9 & 10 & 9 & & \\
\hline Ryhmien lukumäärä & 2 & 2 & 2 & & \\
\hline \multicolumn{6}{|l|}{ Elopaino, kg } \\
\hline -alussa & 175 & 189 & 191 & 2,72 & \\
\hline -lopussa & 616 & 608 & 583 & 13,23 & \\
\hline \multicolumn{6}{|l|}{ Kasvu, $\mathbf{g ~ d}^{-1}$} \\
\hline -päiväkasvu & 1090 & 1040 & 970 & 29,40 & o \\
\hline -nettokasvu & 546 & 540 & 510 & 20,33 & \\
\hline \multicolumn{6}{|l|}{ Rehun kulutus } \\
\hline -syönti, kg ka d ${ }^{-1}$ & 7,33 & 8,23 & 8,18 & 0,14 & $*$ \\
\hline -kg ka/lisäkasvu-kg & 6,75 & 8,00 & 8,45 & 0,16 & $* *$ \\
\hline -kg ka/nettokasvu-kg & 13,54 & 15,39 & 16,11 & 0,40 & $*$ \\
\hline \multicolumn{6}{|l|}{ Teurastulokset } \\
\hline -teuraspaino, kg & 308 & 313 & 302 & 9,25 & \\
\hline -teuras- $\%$ & 50,0 & 51,5 & 51,6 & 0,65 & \\
\hline -lihakkuus ${ }^{3)}$ & $4,4(\mathrm{O}-)$ & $5,0(\mathrm{O})$ & $4,6(\mathrm{O})$ & 0,13 & o \\
\hline -rasvaisuus ${ }^{4)}$ & 2,9 & 2,2 & 2,2 & 0,13 & $*$ \\
\hline
\end{tabular}

\footnotetext{
1) Keskiarvon keskivirhe

2) Tilastollinen merkitsevyys on testattu kontrastein: $\mathrm{C} 1=$ lämmin parsinavetta vastaan kylmät ympäristöt (pihatto + metsätarha), $\mathrm{C} 2=$ pihatto vastaan metsätarhaa, *** $(\mathrm{P}<0.001), * *(\mathrm{P}<0.01), *(\mathrm{P}<0.05), 0(\mathrm{P}<0.1)$

3) EUROP-laatuluokitus, jossa $4=\mathrm{O}-, 5=\mathrm{O}, 6=\mathrm{O}+$ (= kohtalainen lihakkuus)

4) EUROP-laatuluokitus, jossa 2 = ohutrasvainen, $3=$ keskirasvainen
}

Yksi parsisonni oli tervalihainen, minkä johdosta sen ulkofileen pH:n lasku oli teurastuksen jälkeen niin hidas, että lihan raakakypsyminen hidastui jo merkittävästi. Tervalihaisesta ulkofileestä tehtiin kaikki muut analyysit, muttei aistinvaraista arviota. Muiden 11 ruhon jäähtymis- ja pH-arvon alenemisnopeudet olivat normaaleja 24 tunnin kuluessa teurastuksesta. Tulosten mukaan kasvatusym- 
päristö ei vaikuttanut merkitsevästi ulkofileen $\mathrm{pH}$-arvoon tai lämpötilan alenemisnopeuteen teurastusta seuraavien 24 tunnin aikana. Tervalihainen parsisonni ei vaikuttanut keskiarvojen eron merkitsevyyteen, ilmeisesti ruhokohtainen vaihtelu oli kasvatusympäristöä merkittävämpi tekijä. Kasvatusympäristö ei vaikuttanut myöskään ulkofileen valumaan (lihasta irronnut vesi, \%) 21 päivän raakakypsytyksen aikana (taulukko2). Tulosten mukaan ay-sonnien kasvuympäristö vaikutti hieman ulkofileen kemialliseen koostumukseen. Parsieläinten ulkofileessä oli vähiten vettä, mutta eniten lihaksen sisäistä rasvaa. Tämä ero ei kuitenkaan ollut tilastollisesti merkitsevä. Sitä vastoin pihatto- ja tarhaeläinten ulkofileessä oli merkitsevästi enemmän proteiinia $(22,2 \%)$ kuin parsieläimillä $(21,5 \%)(\mathrm{P}<0.05)$.

Tutkittujen ulkofileiden leikkuupinta oli tummin ulkotarhasonneilla (pienin L-arvo), sitten pihattonaudoilla ja vaalein parsieläimillä (suurin L-arvo), erot eivät olleet merkitseviä. Ulkotarhasonnien liha oli merkitsevästi punaisempaa kuin parsisonnien $(\mathrm{P}<0.05)$. Toisaalta kaikki tutkitut naudanlihat olivat väriltään lähes normaaleja: myoglobiinia oli $8,5-14,1 \mathrm{mg} \mathrm{g}^{-1}$, L-arvo vaihteli 33,5 - 43,3 (tervalihaisella sonnilla 33,5; muilla yli 35,0) ja a-arvo oli 20,6 - 30,4. Kirjallisuuden mukaan tervalihan Larvo on alle 34,0; tumman naudanlihan L-arvo on 34,0 tai suurempi, mutta alle 39,0 ja "normaalin" naudanlihan L-arvo on 39,0 tai suurempi, mutta alle 45,0. Rotu, sukupuoli ja naudan ikä vaikuttavat merkittävästi lihan L-arvoon (Lawrie 1985, Miller 1994).

Jokaisesta ulkofileestä tehtiin 20 leikkuuvastemittausta, joiden keskiarvot kasvatusmuodon mukaan on esitetty taulukossa 2 . Tulosten mukaan ay-sonnien kasvatusympäristö ei vaikuttanut ulkofileen leikkuuvasteeseen. Kaikki tutkitut ulkofileet olivat mureudeltaan normaaleja; niiden leikkuuvaste oli alle $10 \mathrm{kp}$. Eläinkohtainen sitkeysvaihtelu ryhmien sisällä oli suuri. Tervalihaisen naudan ulkofileen leikkuuvaste oli suurin (sitkein). Kuitenkaan tervalihaisen sonnin poistaminen laskuista ei vaikuttanut ryhmien väliseen leikkuuvaste-eroihin.

Lihan aistinvaraisessa arvioinnissa ulkofileiden mureus, mehukkuus ja maku arvioitiin asteikolla 1 - 7 pistettä (1 huonoin ja 7 paras). Tervalihaisen parsisonnin ulkofilettä ei arvosteltu sen heikon raakakypsymisen vuoksi. Erot aistinvaraisessa arvostelussa eivät olleet tilastollisesti merkitseviä.

Kasvatusympäristö vaikutti ay-sonnien ulkofileen rasvan rasvahappokoostumukseen (taulukko 2). Monityydyttymättömiä rasvahappoja (P) oli ulkotarhasonneissa merkitsevästi enemmän kuin parsinaudoissa $(\mathrm{P}<0.05)$. Tästä johtuen tarhaeläinten $\mathrm{P} / \mathrm{S}$-suhde oli merkitsevästi suurempi kuin parsieläinten $(\mathrm{P}<0.05)$. Ulkotarhasonnien ulkofileessä oli merkitsevästi vähemmän myristiini- $(\mathrm{C} 14: 0) \mathrm{ja}$ palmitiinihappoa $(\mathrm{C} 16: 0)$ kuin kylmäpihattonaudoissa $(\mathrm{P}<0.05)$. Sitä vastoin pihattoeläimissä oli merkitsevästi enemmän palmitoleiinihappoa $(\mathrm{C} 16: 1)$ kuin tarhaeläimissä $(\mathrm{P}<0.05)$. Ihmiselle välttämättömiä linoli- (C18:2) ja linoleenihappoa (C18:3) oli ulkotarhasonneissa merkitsevästi enemmän kuin parsisonneissa $(\mathrm{P}<0.05$ ja $\mathrm{P}<0.01)$. Myös pihattoeläimiin verrattuna tarhaeläimissä oli enemmän linoleenihappoa $(\mathrm{P}<0.05$; taulukko 2$)$.

\section{Johtopäätökset}

Tulosten perusteella Suomen ilmasto-olosuhteet eivät ole esteenä maitorotuisten lihanautojen ympärivuotiselle ulkokasvatukselle. Maitorotuisia nautoja voidaan kasvattaa myös kylmissä ympäristöissä ilman, että eläinten tuotantotulokset oleellisesti muuttuisivat. Kylmissä olosuhteissa eläinten energiantarve kuitenkin lisääntyy, mikä puolestaan vaikuttaa negatiivisesti rehuhyötysuhteeseen. Tutkimuksen yhteydessä toteutetun eläinten hyvinvointiosion tulosten perusteella kasvatusympäristö tai ilman kylmyys eivät rasittaneet eläimiä niin, että niiden sairastumisherkkyys olisi lisääntynyt (Kauppinen ym. 2002). Tulosten perusteella kasvatusympäristö vaikutti jonkin verran lihan laatuun, erityisesti ulkofileen rasvahappokoostumukseen. Ulkotarhan nautojen lihan sisäinen rasva oli pehmeintä.

\section{Kirjallisuus}

Huuskonen, A., Joki-Tokola, E. \& Huttu, S. 2002. Lihanautojen kasvatus kylmissä tuotantoympäristöissä. Maataloustieteen Päivät 2002. MKL:n julkaisuja no 977. p. 36-39.

Kauppinen, R., Huuskonen, A., Tuomisto, L., Järvikylä, S., Joki-Tokola, E., Lindeberg, H., Sepponen, J. \& Mononen, J. 2002. Lihanautojen hyvinvointi eri kasvatusympäristöissä - tuloksia kasvatuskokeesta kylmäpihatossa, ulkotarhassa ja lämpimässä parsinavetassa. Maataloustieteen Päivät 2002. MKL:n julkaisuja no 977. p. 11-14.

Lawrie, R.A. 1985. Meat Science. Pergamon Press, Oxford ( $4^{\text {th }}$ ed.). 267 p.

Manninen, M., Järvenranta, K. \& Virkajärvi, P. 2002. Erityyppisten kylmien tuotantotilojen soveltuvuus nuorille hf-emoille. Maataloustieteen Päivät 2002. MKL:n julkaisuja no 977. p. 40-43.

Miller, R.K. 1994. Quality characteristics. In: Kinsman, D.M., Kotula, A.W. \& Breidenstein, B.C. (eds.) Muscle foods. Chapman \& Hall, New York. P. 269 - 332. 
Taulukko 2. Ulkofileen koostumus ja laatu sekä ulkofileen rasvahappokoostumus eri kasvatusympäristöissä (keskiarvo \pm keskihajonta).

\begin{tabular}{|c|c|c|c|c|}
\hline & Navetta & Pihatto & Metsätarha & Merkitsevyys ${ }^{1)}$ \\
\hline $\mathrm{n}$ & 4 & 4 & 4 & \\
\hline \multicolumn{5}{|l|}{ Fysiokemialliset ominaisuudet } \\
\hline $\mathrm{pH}, 1 \mathrm{~h}$ teurastuksesta & $6,55 \pm 0,40$ & $6,45 \pm 0,07$ & $6,33 \pm 0,07$ & \\
\hline $\mathrm{pH}, 5 \mathrm{~h}$ teurastuksesta & $5,88 \pm 0,21$ & $5,93 \pm 0,08$ & $5,85 \pm 0,28$ & \\
\hline $\mathrm{pH}, 24 \mathrm{~h}$ teurastuksesta & $5,67 \pm 0,22$ & $5,61 \pm 0,03$ & $5,57 \pm 0,05$ & \\
\hline lämpö $1 \mathrm{~h}$ teurastuksesta, ${ }^{\circ} \mathrm{C}$ & $37,7 \pm 2,2$ & $38,8 \pm 0,5$ & $38,0 \pm 1,2$ & \\
\hline lämpö $5 \mathrm{~h}$ teurastuksesta, ${ }^{\circ} \mathrm{C}$ & $18,3 \pm 2,1$ & $18,2 \pm 0,9$ & $17,3 \pm 2,1$ & \\
\hline lämpö $24 \mathrm{~h}$ teurastuksesta, ${ }^{\circ} \mathrm{C}$ & $3,3 \pm 0,4$ & $2,8 \pm 0,2$ & $3,3 \pm 0,5$ & \\
\hline valuma $21 \mathrm{~d}, \%$ & $0,7 \pm 0,2$ & $0,7 \pm 0,2$ & $0,6 \pm 0,2$ & \\
\hline $\begin{array}{l}\text { myoglobiini, } \mathrm{mg} \mathrm{g}^{-1} \\
\text { väri }\end{array}$ & $10,2 \pm 1,9$ & $11,4 \pm 1,6$ & $12,3 \pm 1,2$ & \\
\hline $\mathrm{L}^{*}$ & $39,8 \pm 4,4$ & $38,2 \pm 1,5$ & $37,7 \pm 1,8$ & \\
\hline$a^{*}$ & $25,8 \pm 3,5^{\mathrm{a}}$ & $29,0 \pm 1,0^{\mathrm{ab}}$ & $29,4 \pm 0,3^{\mathrm{b}}$ & $*$ \\
\hline $\mathrm{b}^{*}$ & $8,9 \pm 2,4$ & $9,7 \pm 0,8$ & $9,6 \pm 0,6$ & \\
\hline leikkuuvaste, $\mathrm{kp} \mathrm{cm}^{-1} \quad$ 3) & $7,0 \pm 1,7$ & $7,4 \pm 1,4$ & $7,7 \pm 1,3$ & \\
\hline \multicolumn{5}{|l|}{ Ulkofileen kemiallinen koostumus } \\
\hline vesi, $\%$ & $73,6 \pm 1,4$ & $73,8 \pm 0,8$ & $73,7 \pm 1,4$ & \\
\hline rasva, $\%$ & $3,5 \pm 1,6$ & $2,8 \pm 0,8$ & $2,6 \pm 1,9$ & \\
\hline proteiini, $\%$ & $21,5 \pm 0,5^{\mathrm{a}}$ & $22,2 \pm 0,1^{\mathrm{b}}$ & $22,1 \pm 0,2^{\mathrm{b}}$ & $*$ \\
\hline \multicolumn{5}{|l|}{ Ulkofileen aistinvarainen arvio $^{4)}$} \\
\hline mureus & $5,6 \pm 0,8$ & $5,1 \pm 1,0$ & $5,0 \pm 1,2$ & \\
\hline mehukkuus & $4,6 \pm 0,9$ & $4,8 \pm 0,8$ & $4,8 \pm 0,9$ & \\
\hline maku & $4,9 \pm 1,2$ & $4,6 \pm 0,8$ & $4,8 \pm 0,9$ & \\
\hline yhteispisteet & $15,1 \pm 2,4$ & $14,6 \pm 2,1$ & $14,6 \pm 2,1$ & \\
\hline \multicolumn{5}{|c|}{ Ulkofileen rasvahappokoostumus, $\%$} \\
\hline C12:0 (Lauriinihappo) & $0,1 \pm 0,1$ & $0,1 \pm 0,0$ & $0,1 \pm 0,1$ & \\
\hline C14:0 (Myristiinihappo) & $2,7 \pm 0,6^{\mathrm{ab}}$ & $3,2 \pm 0,1^{\mathrm{a}}$ & $2,4 \pm 0,2^{\mathrm{b}}$ & $*$ \\
\hline C16:0 (Palmitiinihappo) & $26,1 \pm 2,1^{\mathrm{ab}}$ & $27,4 \pm 0,5^{\mathrm{a}}$ & $24,4 \pm 1,4^{\mathrm{b}}$ & $*$ \\
\hline C16:1 (Palmitolihappo) & $3,2 \pm 0,4^{\mathrm{ab}}$ & $3,6 \pm 0,6^{\mathrm{a}}$ & $2,9 \pm 0,3^{\mathrm{b}}$ & $*$ \\
\hline C17:0 (Heptadekaanihappo) & $0,8 \pm 0,1$ & $0,9 \pm 0,1$ & $0,9 \pm 0,1$ & \\
\hline C18:0 (Steariinihappo) & $16,2 \pm 2,0$ & $15,3 \pm 1,4$ & $17,5 \pm 1,6$ & \\
\hline C18:1 (Öljyhappo) & $40,3 \pm 2,5$ & $36,6 \pm 2,6$ & $38,3 \pm 4,4$ & \\
\hline C18:2 (Linolihappo) & $2,1 \pm 0,4^{\mathrm{a}}$ & $2,5 \pm 0,6^{\mathrm{ab}}$ & $3,1 \pm 0,5^{\mathrm{b}}$ & $*$ \\
\hline C18:3 (Linoleenihappo) & $0,5 \pm 0,0^{\mathrm{a}}$ & $0,6 \pm 0,1^{\mathrm{a}}$ & $0,8 \pm 0,1^{\mathrm{b}}$ & $* *$ \\
\hline C20:0 (Arakidiinihappo) & $0,1 \pm 0,0^{\mathrm{a}}$ & $0,1 \pm 0,1^{\mathrm{ab}}$ & $0,2 \pm 0,1^{b}$ & * \\
\hline C20:1 (Eikoseenihappo) & $0,2 \pm 0,0$ & $0,2 \pm 0,1$ & $0,2 \pm 0,0$ & \\
\hline C20:2 (Eikosadieenihappo) & $0 \pm 0,1$ & $0,1 \pm 0,1$ & $0 \pm 0,1$ & \\
\hline C20:4 (Arakidonihappo) & $0,4 \pm 0,1$ & $0,5 \pm 0,1$ & $0,6 \pm 0,2$ & \\
\hline C22:5 (Dokosapentaeenihappo) & $0,2 \pm 0,0$ & $0,2 \pm 0,0$ & $0,2 \pm 0,1$ & \\
\hline U (Tunnistamattomat rasvahapot, \%) & $7,2 \pm 0,4$ & $8,8 \pm 1,2$ & $8,6 \pm 1,7$ & \\
\hline S (Tyydyttyneet rasvahapot, \%) & $46,0 \pm 2,5$ & $46,9 \pm 1,5$ & $45,3 \pm 2,5$ & \\
\hline $\mathrm{M}^{5)}$ & $43,7 \pm 2,4$ & $40,5 \pm 2,9$ & $41,4 \pm 4,5$ & \\
\hline $\mathrm{P}^{6)}$ & $3,2 \pm 0,5^{\mathrm{a}}$ & $3,8 \pm 0,9^{\mathrm{ab}}$ & $4,7 \pm 0,9^{b}$ & $*$ \\
\hline $\mathrm{P} / \mathrm{S}^{7)}$ & $0,07 \pm 0,0^{\mathrm{a}}$ & $0,08 \pm 0,0^{\mathrm{ab}}$ & $0,10 \pm 0,0^{\mathrm{b}}$ & $*$ \\
\hline $\mathrm{M} / \mathrm{S}^{8)}$ & $0,95 \pm 0,1$ & $0,86 \pm 0,1$ & $0,92 \pm 0,2$ & \\
\hline$(\mathrm{M}+\mathrm{P}) / \mathrm{S}^{9)}$ & $1,02 \pm 0,1$ & $0,95 \pm 0,1$ & $1,02 \pm 0,1$ & \\
\hline \multicolumn{5}{|c|}{$\begin{array}{l}\text { 1) Tilastollinen merkitsevyys: *** }(\mathrm{P}<0.001), * *(\mathrm{P}<0.01), *(\mathrm{P}<0.05), \text { o }(\mathrm{P}<0.1) \text {. Toisistaan merkitsevästi }(\mathrm{p}<0.05) \\
\text { poikkeavat keskiarvot on merkitty eri yläindeksillä. }\end{array}$} \\
\hline \multicolumn{5}{|c|}{$\begin{array}{l}\text { 2) } \begin{array}{l}* \\
\text { lenäyte) }\end{array}\end{array}$} \\
\hline \multicolumn{5}{|c|}{ 3) Määritetty leikkuumittarilla, mitä suurempi luku, sitä sitkeämpää liha on } \\
\hline \multicolumn{5}{|c|}{ 4) Subjektiivinen arvostelu, jossa 1 = erittäin huono ja 7 = erittäin hyvä } \\
\hline \multicolumn{5}{|c|}{${ }^{5)} \mathrm{M}=$ Kertatyydyttymättömät rasvahapot, \% } \\
\hline \multicolumn{5}{|c|}{ 6) $\mathrm{P}=$ Monityydyttymättömät rasvahapot, \% } \\
\hline \multicolumn{5}{|c|}{ 7) $\mathrm{P} / \mathrm{S}=$ Monityydyttymättömät / Tyydyttyneet -suhde } \\
\hline \multicolumn{5}{|c|}{${ }^{8)} \mathrm{M} / \mathrm{S}=$ Kertatyydyttymättömät / Tyydyttyneet -suhde } \\
\hline 9) $(\mathrm{M}+\mathrm{P}) / \mathrm{S}=($ Kertatyydyttymättömät + & Monityydyt & 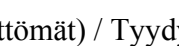 & & \\
\hline
\end{tabular}

